\title{
Zu einer Ethik der Ästhetik in pandemischen Zeiten $^{1}$
}

\section{Towards an Ethics of Aesthetics in Pandemic Times}

\section{DAVINA HöLl, TÜBINGEN}

Zusammenfassung: Seit Langem sieht die Welt sich wieder einer globalen pandemischen Bedrohung ausgesetzt, die nicht nur wissenschaftlich, wirtschaftlich, politisch und gesellschaftlich, sondern auch künstlerisch zu bewältigen versucht wird. Dabei dominieren vor allem zwei visuelle Phänomene die Bildwelten der journalistischen und sozialen Medien: das Bild der Maske und das Bild des Virus selbst. Beide Bilder sind insbesondere in der Verbindung mit epi- und pandemischer Erfahrung bereits hoch aufgeladen. Die Sichtbarkeit der Maske und die Sichtbarmachung des Virus verweisen auf ihre komplexen (kultur)historischen Dimensionen und rufen philosophisch-ethische Fragen auf. Durch eine Gegenüberstellung von künstlerischen Zeugnissen historischer und gegenwärtiger Seuchenerfahrung werden im vorliegenden Beitrag historisch tradierte Muster von narrativen und visuellen Seuchendarstellungen, die auch den gegenwärtigen Pandemiediskurs bestimmen, herausgearbeitet und kritisch hinterfragt. Dabei wird gefragt, wie Kunst und Literatur zu einer rhetorischen und metaphorischen Deeskalation aktueller und zukünftiger pandemischer Krisendiskurse beitragen und damit auch eine der Ästhetik inhärente Ethik aufzeigen können.

Schlagwörter: Ethik, Ästhetik, Pandemien, Narrativ, Visualisierung

Abstract: For a long time now, the world has once again been confronted with a global pandemic threat, which is being addressed not only scientifically, economically, politically, and socially, but also artistically. Two visual phenomena, in particular, can be identified that dominate the visual worlds of journalistic and social media: The

1 Ich bedanke mich herzlich bei den anonymen GutachterInnen für ihre kritischen Nachfragen und hilfreichen Anmerkungen. 
image of the mask and the image of the virus itself. Both images are already highly laden with meaning, especially in combination with epi- and pandemic experience. The visibility of the mask and the visualization of the virus refer to their complex (cultural) historical dimensions and call up philosophical-ethical questions. By juxtaposing artistic testimonies of historical and current epidemic experiences, this article will examine and critically question historically handed-down patterns of narrative and visual depictions of epidemics, which also determine the current pandemic discourse. In conclusion, the paper will investigate how art and literature may contribute to a rhetorical and metaphorical de-escalation of current and future pandemic crisis discourses and thus also reveal an ethic inherent in aesthetics.

Keywords: ethics, aesthetics, pandemics, narrativization, visualization

Mit dem Ausbruch von Covid-19 sieht sich die Welt seit Langem wieder einer globalen pandemischen Bedrohung ausgesetzt, die nicht nur wissenschaftlich, wirtschaftlich, politisch und gesellschaftlich, sondern auch künstlerisch zu bewältigen versucht wird. Namhafte Autorinnen und Autoren, Künstlerinnen und Künstler, aber auch Kultur schaffende Laien arbeiten sich humoristisch, besorgt, zuversichtlich oder kritisch-kreativ an den gegenwärtigen Herausforderungen ab (Grünbein 2020; Emcke 2020; Bruner 2020; Dorn 2021). Es entstehen eine enorme Anzahl von digitalen wie analogen Kunstprodukten (vgl. z. B. \#coronoaart). Bereits zu Beginn der Pandemie fanden zahlreiche, oft interaktive Kunstaktionen im Internet oder in der auf Abstand gehaltenen Öffentlichkeit, wie von Balkonen und Türschwellen gespielte Nachbarschaftskonzerte, statt und neue digitale Formate wurden für Museen, Opernhäuser und Theater entwickelt. Die Krise hat aber nicht nur einen ganz spezifischen künstlerischen Aktionismus hervorgerufen, sondern auch eine eigene Bildlichkeit geschaffen. Dabei lassen sich vor allem zwei dominante visuelle Phänomene ausmachen, die die Bildwelten der journalistischen und sozialen Medien beherrschen: das Bild der Maske und das Bild dessen, wovor sie schützen soll, nämlich des Virus selbst. Sie sind zu Emblemen der aktuellen Seuchenerfahrung geworden. Die Sichtbarkeit der Maske und die Sichtbarmachung des Virus verweisen dabei auf ihre komplexen (kultur)historischen Dimensionen und rufen philosophisch-ethische Fragen auf. Durch eine Gegenüberstellung von künstlerischen Zeugnissen historischer und gegenwärtiger Seuchenerfahrung werden im vorliegenden Beitrag tradierte Muster von narrativen und visuellen Seuchendarstellungen, die auch den gegenwärtigen Pandemiediskurs bestimmen, kritisch hinterfragt sowie genuine Formen künstlerischer und literarischer Bewältigungsstrategien diskutiert, 
die eine sich transformierende Welt aktiv mitzugestalten versuchen. So soll gezeigt werden, wie alternative künstlerisch-literarische Anverwandlungsprozesse des Virus zu einer rhetorischen und metaphorischen Deeskalation aktueller und zukünftiger pandemischer Krisendiskurse beitragen können, und damit auch nach einer der Ästhetik inhärenten Ethik fragen.

\section{Die Maske}

Die Omnipräsenz der Maske führt permanent den Problemkomplex einer ,neuen Normalität‘ im Zeichen von Ansteckungsgefahr und Ansteckungsvermeidung vor. Am Anfang der Pandemie für den alltäglichen Gebrauch und persönlichen Schutz noch als kaum nützlich beurteilt, später weltweit vergriffen und schließlich massenhaft in Eigenproduktion hergestellt, ist sie Symbol für Pluralität und Dynamik wissenschaftlicher Erkenntnisbildung und -kommunikation, die für Teile der Gesellschaft noch immer schwer zu akzeptieren ist. Sie ist Pars pro Toto eines ganzen Arsenals von Verhaltensregeln, die, so hofften einige, nur für kurze Zeit unsere gewohnten zwischenmenschlichen Interaktionen irritieren würden, inzwischen aber zu einem festen Bestandteil sozial erwünschter Verhaltensweisen geworden sind. Das Bundesministerium für Gesundheit hat diese im Sommer 2020 in der bündigen AHA-Formel zusammengefasst. Mit Abstand, Hygiene und Alltagsmaske sollten die Menschen in Deutschland nicht nur "gut durch den Sommer" kommen, sondern auch in einen „neuen Alltag" finden (Bundesministerium für Gesundheit 2020). Die Maske ist beständige Erinnerung an den andauernden Ausnahmezustand, Mahnung zur Achtsamkeit und kategorischer Imperativ solidarischen Verhaltens, der auch nach Einführung der 3-G-Regel (gimpft, gestet, genesen) weiterhin Gültigkeit hat. Doch wird sie nicht nur als, mitunter unbequemes, Schutzinstrument gesehen, sondern ist ein regelrechtes Politikum. Das Verdecken des Mundes wird als Unterdrückungsakt angeprangert, der nicht nur physiologisch den Vorgang des Sprechens behindert, sondern als Stoff gewordener Ausdruck machtpolitischen Interesses versucht, Individualität einzuschränken und freie Meinungsäußerung - und sukzessive weitere Grundrechte - außer Kraft zu setzen. Das (demonstrative) Nichttragen der Maske, also ihre Abwesenheit, hat inzwischen einen ebenso starken Symbolcharakter erlangt wie ihre Präsenz. Im assoziativen Rückgriff auf die ikonisch gewordenen Pest-Masken, die, obgleich ihre Verwendung erst ab dem 17. Jahrhundert anhand medizinhistorischer Quellen belegbar ist (Ruisinger 2020, 245), bis heute wenig von ihrer 
Unheimlichkeit verloren haben, evozieren auch die deutlich freundlicheren Masken der pandemischen Gegenwart die kollektivtraumatische Erfahrung des ,Schwarzen Todes‘, als ,Mutter aller Seuchen'. Es fällt auf, dass auch die gegenwärtige Pandemie sprachlich wie visuell vielfach im tradierten narrativen Gewand der Pestbeschreibungen vermittelt wird, die mit Giovanni Boccaccios (1313-1375) Klassiker des weltliterarischen Epidemien-Kanons, Decameron, zur Blaupause und zum veritablen outbreak narrative (Wald 2008) geworden sind. Die Seuchenbeschreibungen Boccaccios, die sich auch aus der literarischen Tradition der Epidemie-Beschreibungen der vorangegangenen Jahrhunderte speisen, sind zu einem literarischen Paradigma geworden. Die klassischen Topoi der Seuche sind dabei ihre Herkunft aus der Fremde - vornehmlich aus dem Osten -, ihre schnelle und großflächige Ausbreitung, das massenhafte Sterben, das Sitten verrohen und politische und soziale Ordnungen verfallen lässt, das Hervorrufen epistemischer und praxeologischer Krisen und oft eine spezifische Unsagbarkeit der grauenhaften Krankheitserscheinung und -erfahrung. Diese finden sich in großer Zahl in populärer Massenliteratur und den Klassikern der Seuchenliteratur, die in den Jahrhunderten nach Boccaccios Decamerone entstanden sind, wie in Daniel Defoes A Journal of the Plague Year (1722), Alessandro Manzonis I promessi sposi (1826), Edgar Allan Poes Erzählung The Masque of the Red Death (1842) oder Albert Camus' La peste (1947). Auch hat der Prototyp kollektivtraumatischer Pandemie-Erfahrung die Kunstgeschichte tief geprägt und die Anfänge einer epidemischen Ikonographie markiert (Boeckl 200o).

Die Maske fasziniert die Kunst- und Kulturgeschichte, nicht nur im Kontext der Pest, schon seit Langem. Insbesondere das Paradox von Zeigen und Verhüllen, von Identitäts- und Individualitäts(de)konstruktionen ist Gegenstand zahlreicher wissenschaftlicher Abhandlungen (Weihe 2004; Hüls 2013; Belting 2013). Dabei gerät immer wieder auch die besondere Verbindung von Maske und Tod in den Blick. Die „fundamentale Bedeutung“ der „thanatologischen Dimension der Maskenthematik“ (Weihe 2004, 20) findet sich weltweit in kulturellen Zeugnissen, die einen „Zusammenhang zwischen Masken und Tod, den schon die Starrheit der Maske nahelegt“ (ebd.), aufzeigen, denn die Maske war schon in prähistorischer Zeit der Versuch, „an der Leiche ein verlorenes Gesicht wieder herzustellen“ (Belting 2013, 10). Später bot der karnevaleske Maskenball „der Figuration des Todes mit Maske“ (Schonlau 2009, 65) eine besonders geeignete Bühne. Er erweiterte das ikonographische Repertoire des Totentanzes, der als „bildlich-literarische Gattung“ (Schulte 2007, 658) im Spätmittelalter inspiriert von orienta- 
lischen Legenden entstanden war (F.H. Link 1993, 12) und insbesondere in der Verbindung mit monumentalen Seuchenerfahrungen einen festen Platz in der kulturellen Imagination um das „Motiv des maskierten Seuchentods“ (Schonlau 2009, 62) hat. In ihrer Analyse des Zusammenhangs zwischen Maske, Tod und Seuche am Beispiel der Syphilis verweist die Literaturwissenschaftlerin Anja Schonlau zudem darauf, dass insbesondere „Fastnachtsmasken semantisch nicht nur dem Tod [...], sondern auch Krankheiten“ nahestanden und ihre Träger nicht nur die Rolle der „Totenseele, sondern auch die des Krankheitsträgers" (Schonlau 2009, 63) einnehmen konnten. Im 19. Jahrhundert hat die imaginative Parallelisierung der Cholera mit der Pest zur Wiederbelebung der Kombination von Seuche und Totentanz im Maskenball geführt.

\section{Cholera und Corona}

Ein besonders eindrückliches Beispiel dieser Verbindung findet sich in Heinrich Heines (1797-1856) Cholera-Bericht in Französische Zustände aus den Jahren 1831/32 (Heine 1980, 129-151). Der sechste von neun längeren Artikeln wurde wenige Wochen nach dem ersten Ausbruch der Cholera in der französischen Hauptstadt am 19. April 1832 verfasst. In diesem Bericht kommt der Maske, und vor allem dem ,Dahinter', eine besondere Rolle zu.

Die Cholera war die Leitkrankheit des 19. Jahrhunderts. Sie wurde zur wissenschaftlichen Triebkraft und zur politischen und gesellschaftlichen Zerreißprobe sowie zur Herausforderung allgemeinsprachlicher und poetologisch-künstlerischer Vermittlung. Hochinfektiös, rapide fortschreitend und bei Nichtbehandlung mit einer hohen Letalitätsrate konnte die Cholera innerhalb kürzester Zeit, unter Krämpfen, großen Schmerzen und auf als abstoßend empfundene Weise zum Tod führen. Wissenschaft und Politik sahen sich angesichts der Seuche mit einem vollkommenen „Mysterium“ (Briese 2003, 45) konfrontiert. Wie heute angesichts von Covid-19 rang die Wissenschaft dabei um Erklärungen für die Entstehung, Verbreitung und um Therapie- und Präventionsmaßnahmen. Indem die monumentale Seuchenerfahrung der Cholera den Beweis über die Existenz von krankmachenden Mikroorganismen erzwungen hatte, gelang es Robert Koch (1843-1910) als dem Entdecker des Vibrio cholerae und dem Begründer der modernen Bakteriologie schließlich, ein ganz neues Kapitel in der Medizin aufzuschlagen. Das unermüdliche Forschen an dem Jahrhunderträtsel der Cholera hat bedeutend zu der Herausbildung der medizinischen Mikrobiologie beigetragen, also jener wissenschaftlichen Disziplin, deren Teilgebiet der Virologie 
sich heute zuvorderst an der Herausforderung des neuartigen Coronavirus abarbeitet. Noch heute ist das Robert-Koch-Institut (RKI) die maßgebliche Instanz, die das gegenwärtige Seuchengeschehen in Deutschland wissenschaftlich überwacht, bewertet und Handlungsanweisungen für die Bevölkerung ableitet.

Heinrich Heine beschreibt in seiner journalistischen Novelle, die im Gewand eines journalistischen Tatsachenberichts daherkommt, jedoch merklich durchsetzt mit fiktionalen Elementen ist, wie die Cholera ausgerechnet auf dem Höhepunkt des Pariser Karnevals ausbricht. Schon seit einiger Zeit berichten die Nachrichten über einen unsichtbaren Feind, der aus dem Osten kommt und sich über die ganze Welt ausbreitet. Die Seuche beherrscht die Lebens- und Vorstellungswelten der Menschen. Unwissenheit und Unsicherheit dominieren, drastische Quarantänemaßnahmen werden verhängt, Grenzen geschlossen. Schiffe liegen in den Häfen vor Anker, Kranke werden isoliert, Sperrzonen markiert. Spezielle Krankenhäuser werden eilig errichtet, denn die Zahl der Infizierten wächst unkontrollierbar und droht, die Kapazitäten des regulären Gesundheitssystems zu sprengen. Wird die Gefahr zunächst auch verschwiegen oder heruntergespielt, bricht bald überall Angst und Panik unter der Bevölkerung aus. Um Aufklärung und Eindämmung ringende politische wie medizinische Autoritäten haben dem wenig entgegenzusetzen. Und während der Ausnahmezustand verhängt und der Krieg gegen die Seuche ausgerufen wird, ziehen sich die einen in die totale Isolation zurück und die anderen geben sich angesichts der scheinbar unmittelbar bevorstehenden Apokalypse dem Exzess hin. Es ist Karnevalszeit, als die Seuche ihren ersten großen Auftritt hat. Wir schreiben das Frühjahr 1832 und die asiatische Cholera ist im Zentrum Europas angekommen.

Heine schildert die Cholera als neue Grande Terreur, die als mysteriöser „verlarvter Henker“ durch die Straßen der Stadt streift und ihre Opfer wie mit Hilfe einer portablen Guillotine ,hinrichtet‘. Sich auf die literarischen Gewährsmänner der großen Seuchenbeschreibungen Thukydides und Boccaccio berufend, verdichtet er in einem einzigen Abschnitt sämtliche Schrecken der Cholera. Dabei überblendet Heine das bunte Karnevalstreiben, das gerade in der Stadt begonnen hatte und an sich bereits einem Ausnahmezustand gleichkam (Bachtin 1995, 139), mit nahezu allen Facetten des zeitgenössischen Cholera-Diskurses und travestiert es zu einem effektvollen Totentanz: 
Ihre Ankunft war den 29. März offiziell bekannt gemacht worden, und da dieses der Tag des Mi-Carême und das Wetter sonnig und lieblich war, so tummelten sich die Pariser um so lustiger auf den Boulevards, wo man sogar Masken erblickte, die, in karikirter Mißfarbigkeit und Ungestalt, die Furcht vor der Cholera und die Krankheit selbst verspotteten. Desselben Abends waren die Redouten besuchter als jemals; übermüthiges Gelächter überjauchzte fast die lauteste Musik, man erhitzte sich beim Chahut, einem nicht sehr zweydeutigen Tanze, man schluckte dabey allerley Eis und sonstig kaltes Getrinke: als plötzlich der lustigste der Arlequine eine allzu große Kühle in den Beinen verspürte, und die Maske abnahm, und zu aller Welt Verwunderung ein veilchenblaues Gesicht zum Vorscheine kam. (Heine 1980, 133-34)

Erhoffen sich die einen von ihren Karnevalsmasken, die durch ihre „Mißfarbigkeit und Ungestalt“ die Angst vor der Seuche und diese selbst verlachen, gewissermaßen (anti)ästhetische Schutzfunktion, zeigt sich in der Demaskierung des „lustigste[n] der Arlequine“ das Gegenteil. Das blau verfärbte Gesicht des Harlekins ist ein untrügliches Zeichen für eine Cholera-Infektion, bei der sich durch den starken Verlust der Körperflüssigkeiten die Körpertemperatur rapide absenkt und eine Blaufärbung des Gesichts und der Extremitäten eintritt. Hinter der Maske des Harlekins offenbart sich nicht weniger als das Gesicht der Cholera selbst, das wiederum das Gesicht des Harlekins zur „veilchenblauen“ Maske erstarren lässt.

In Deutschland war es erneut der Bericht über den Ausbruch einer unbekannten Krankheit auf einem Karnevalsfest, das sich zwar nicht in einer europäischen Metropole, sondern in einer Kleinstadt in der nordrhein-westfälischen Provinz ereignete, der die Ankunft einer neuen Seuche ins Zentrum der medialen Aufmerksamkeit rückte. Es ist das Frühjahr 2020, als Corona im Zentrum Europas ankommt. War das veilchenblaue Gesicht der Cholera-Infizierten Symbol für die Schrecken der historischen Seuche und galt es, die Seuche mit Flanellbinden - „dem besten Panzer gegen die Angriffe des schlimmsten Feindes“ (Heine 1980, 139) - abzuwehren, ist es heute die schneeglöckchenweiße FFP2-Maske derjenigen, die sich und vor allem die anderen vor dem Coronavirus zu schützen versuchen.

\section{Tod und Maske}

So wird auch im Kontext von Pandemien die Maske zu einem Paradoxon. Zum einen steht sie insbesondere im Angesicht einer noch weitestgehend unerklärlichen Seuche symbolisch für das unbekannte ,Dahinter 
Nichtsichtbare und das Nichtvorhersehbare des akuten pandemischen Geschehens: Was löst die Seuche aus, wie verbreitetet sie sich, wie kann man sich schützen, was bringt Heilung, welche sozialen, wirtschaftlichen, politischen und wissenschaftlichen Folgen wird sie haben? Sie ist damit unheimliche Mahnerin der (post)pandemischen Bedrohungen. Zum anderen ist sie Symbol des Schutzes vor ebendiesen Bedrohungen. Spätestens seit dem 17. Jahrhundert lässt sich die (teilweise) Verhüllung des Kopfes zum Schutz vor Ansteckung insbesondere in Seuchenzeiten in medizinhistorischen Quellen nachweisen (Ruisinger 2020, 239). Die Pestarztmaske aus dieser Zeit ist zur Ikone historischer Seuchenerfahrung geworden. Tatsächlich war es wieder ein Pestausbruch, nämlich der der Lungenpest in der Mandschurei der Jahre 1910-1911, der jene Form der Schutzmaske hervorgebracht hat (Lynteris 2018, 444), die nun Ikone der gegenwärtigen Pandemie ist und emblematisch für die Bedrohung einer einst als postpandemisch imaginierten Zukunft steht. Die seit dem späten 19. Jahrhundert durch die Allianz von wirksamen Methoden der Desinfektion, der Entwicklung immer neuer Impfstoffe sowie der Entdeckung und Verfügbarmachung von zahlreichen antimikrobiellen Substanzen, allen voran der Antibiotika, entstandene Hoffnung, dass das Ende der Infektionskrankheiten gekommen sei, hat sich nicht bestätigt. Im Gegenteil sind bekannte, zum Teil hoch letale, aber auch neue, so genannte „Emerging Infectious Diseases (EIDs)“ wie das neue SARS-CoV2-Virus, heute mehr denn je „a significant burden on global economies and public health“ (K.E. Jones u.a. 2008, 990). Zwischen 1940 und 2004 wurden 335 neue Infektionskrankheiten verzeichnet (ebd.). In den vergangenen Jahren haben die Ausbrüche von SARS (2002-2003), der Schweinegrippe (2009-2010), Ebola (2014-2016) und Zika (2015-2016) mehrfach die permanente Gefahr durch Epidemien und Pandemien demonstriert.

Ob klinisch blau-weiß, bunt gemustert, Strass besetzt, aus Vlies, Seide oder aus Xylinum, das medizin-, kultur- und kunstgeschichtliche Erbe der ambivalenten Verbindung von Tod und Maske macht diese als Memento mori zu einem eindrucksvollen Emblem auch der gegenwärtigen PandemieErfahrung: „Portrayed as the last barrier between us and the killer virus to come, ,plague masks' ultimately transform us into a species inhabiting the anteroom of its own extinction." (Lynteris 2018, 452) 


\section{Maskenkunst als Kommunikationsmittel}

Die Maske ist so ein „Kommunikationsmittel“ (Weihe 2004, 18), das qua ihrer Zeichenhaftigkeit eine Nachricht zu transportieren vermag, die sowohl einen Sender als auch einen Empfänger voraussetzt. Die Maske als Emblem der gegenwärtigen Pandemie scheint wenig ambivalent, denn ihr ist ein klarer Zweck zugeordnet. Als Mund-Nasen-Schutz soll sie Träger und dessen Gegenüber vor Ansteckung schützen. Und doch ist sie gesellschaftliche Projektionsfläche, Indikator politischer Standortbestimmung und wissenschaftliches Experimentierfeld und macht nicht zuletzt die enge Verbindung künstlerischen und kulturellen Schaffens angesichts existentieller (Seuchen-)Bedrohungen deutlich. In der Maske als „ein[em] universelle[n] Phänomen [...], ein[em] seit der Frühzeit der Menschheit bezeugte[n] Kulturprodukt" (Weihe 2004, 16), das in seinem Variantenreichtum und seinem Interpretationspotenzial nahezu unerschöpflich ist (Belting 2013, 33), ist die Verzahnung von Funktion und Form, von Pragmatik und Ästhetik $a b$ ovo angelegt und das lässt sie permanent zwischen rituellem Gegenstand, Distinktionsmerkmal, Schutzinstrument und künstlerischem Artefakt oszillieren. Dieser Ambiguität der Maske ist in Zeiten von Corona auch künstlerisch vielfach begegnet worden, wie sich in einer nahezu unüberschaubaren Bilderflut vor allem in den sozialen Medien zeigt. In dem offenkundig starken Bedürfnis nach künstlerischem Produzieren und Rezipieren zeigt sich auch das Bedürfnis nach der Handlungsmacht, die Kunst bietet. Das Tragen der Maske in bestimmten Teilen des öffentlichen Lebens ist nach kontroversen Diskussionen seit dem 29. April 2020 in Deutschland zu einem verpflichtenden Akt geworden. Ein Zuwiderhandeln kann rechtliche Konsequenzen haben und mit einer Geldstrafe geahndet werden. Durch die Unabdingbarkeit der Masken-Maßnahme geht, zumindest gefühlt, individuelle Handlungsmacht verloren. Die individuelle, künstlerisch-produktive Auseinandersetzung aber kann diese verloren geglaubte Handlungsmacht zurückgeben und entwickelt diese dabei selbst. Bilder von Masken, Masken auf Bildern sowie Bilder auf Masken visualisieren die Komplexität der gegenwärtigen Pandemie-Erfahrung und ermöglichen es gleichzeitig, dieser zu begegnen. Sie generieren Aufmerksamkeit, üben Kritik und fordern gleichsam kritisches Denken und Handeln ein, sie sensibilisieren für die Diversität, Multiplizität und Differenziertheit der Leiderfahrung und fordern Empathie mit dieser ein. Sie sind eskapistisches Spiel, kultur-ironischer Kommentar und nicht zuletzt Ausdruck für das ,Dahinter ' der Maske, die Individualität dessen, der sie trägt. In der künstlerischen und damit auch ästhetisierenden Bear- 
beitung der Kollektiverfahrung wird deutlich, dass diese immer auch Individualerfahrung ist und auch Kollektivsymbole (J. Link 1988, 286), wie die Maske, individuell lesbar und codierbar sind. Die vielfältigen Lesarten und Codierungen der Maske in Zeiten von Corona sind so in den letzten Monaten bereits Gegenstand einer Reihe von historischen, philosophischen und kulturwissenschaftlichen Analysen geworden (Ruisinger 2020; Strasser und Schlich 2020; Flaskerud 2020; Goh u. a. 2020; Matuschek u. a. 2020) und wurden in zahlreichen journalistischen Artikeln besprochen (Dusl 2020; Friedmann 2020; Hindhal 2020; Marchal 2020). Um das zweite Emblem der gegenwärtigen pandemischen Bedrohung, nämlich das Bild des Virus, ist es lange still geblieben. Dabei ist auch jenes hochkomplex aufgeladen, hat eine lange Geschichte und wirft eine ganz andere Art ethischer Frage auf, nämlich die nach einer Ethik der Ästhetik des wissenschaftlichen Bildes.

\section{Das Virus}

Das zweite Emblem der Pandemie, die gekrönte Kugel meist in Gelb, Rot, Orange und Grau, entstand im Auftrag des Centers for Disease Control and Prevention (C.D.C.), der zentralen Behörde des US-amerikanischen Gesundheitsministeriums. Sie wurde von den beiden medizinischen IllustratorInnen Alissa Eckert und Dan Higgins angefertigt. Ende Januar 2020 erhielten sie die Aufgabe, so Eckert in einem New-York-Times-Interview, einen „,beauty shot': a detailed, solo close-up" des Virus zu realisieren, um dem noch weitestgehend unbekannten Pathogen eine „Identität“ zu verleihen und so öffentliche Aufmerksamkeit zu generieren (Giaimo 2020). In weniger als einer Woche ist das Einzelportrait des Virus entstanden, das als so genannter ,Spiky Blob` seit seinem ,Release“ die visualisierten Imaginationen des Virus, „ubiquitous in both its original and in many mutations across print, television, and online media, including especially social media“ (Bailey 2020a) bestimmt. Ausgehend von der kugeligen mit unterschiedlichen Proteinen besetzten Grundform, die allen Viren eigen ist, haben Eckert und Higgins mithilfe verschiedener Software-Programme, allen voran Autodesk 3ds Max, „where all the magic happens" (Giaimo 2020), mit unterschiedlichen Farben, Texturen und Lichtverhältnissen experimentiert. Sie entschieden sich für eine „steinige“ Textur, damit es so aussah, als ob man das Virus geradezu berühren könne. Die Schatten, die die namensgebenden ,Spikes' werfen, sollten den Ernst der Lage demonstrieren. Da zur gleichen Zeit im Auftrag der C.D.C. an weiterem visuellen Covid-19-Material zu Kommunikations- 
zwecken gearbeitet wurde, musste die Illustration mit dem ,Branding“ der Behörde korrespondieren. Also probierten sie verschiedene Varianten eines vorgegebenen Farbschemas aus: „Red on grey, with orange and yellow accents, was the most arresting: ,It just really stood out.““ (Giaimo 2020) Das entstandene Portrait des Virus, das schnell dem vor allem durch Unkenntnis, Ungewissheit und Unberechenbarkeit markierten Erreger eine, und zwar bis heute die einzige, fassbare Form zu geben scheint, ist inzwischen zur Ikone geworden und hat sich wie das Virus selbst unaufhaltsam über die ganze Welt verbreitet. Es ist im wortwörtlichen Sinne,viral' gegangen. Das ,Gesicht der neuen Pandemie, das selbst gesichtslos bleibt, wird emotional diskutiert. Während vor allem immer wieder die Objektivität der Darstellung in Frage gestellt wird, wird auch die Funktionalität kritisiert: Dem amerikanischen Kunstwissenschaftler Robert Bailey erscheint das Bildnis des ,Spiky Blob“ in seiner unmenschlichen Ästhetik zu schrecklich, den Medizinrhetorikerinnen Kristin Marie Bivens und Marie Moeller ist es zu ästhetisch, um Schrecken zu verbreiten. Doch ist der ,Spiky Blob“ nicht nur ein künstlerisches Portrait, das in unzähligen Variationen ein veritables Eigenleben entwickelt hat, er ist auch ein wissenschaftliches Bild, das genrebedingt zwischen den „beiden Kulturen“ der Kunst und der Wissenschaft (Snow 1993), die trotz vieler theoretischer wie praktischer Versuche heute oft noch als getrennt angesehen werden, operiert. Das wissenschaftliche Bild stellt damit nicht nur kunstund bildwissenschaftliche sowie epistemologische Analysen vor eine große Herausforderung, sondern fragt auch danach, was Kunst im Kontext szientifischer Wissensgenerierung und -kommunikation kann und darf.

\section{„still bigger picture [...] and yet-grander imagination“}

Robert Bailey hat sich intensiv mit der Visualisierung des Virus auseinandergesetzt und eine detaillierte Bildanalyse vorgelegt (Bailey 2020a; 2020b). Neben der dezidiert Gefahr vermittelnden Farbgebung hebt er den beängstigenden Realitätseffekt hervor, den die Belichtung und Schattierungen erzeugen. Die Dreidimensionalität der Darstellung lasse die Ränder des Virus verschwommen erscheinen und erwecke den Eindruck, als ob „those more proximate to us [...] push out from our screens into our reality, threatening us physically“. Die absolute Unspezifität der Darstellung des „Spiky Blob“, der tatsächlich weder „spiky“ noch „blob-shaped“ sei, erlaube es, ihn mit jedweder Bedeutung aufzuladen und generiere vor allem Angst. Dem Portrait des Virus als ,Spiky Blob“, das in seiner Bedrohlichkeit an einen Todesstern aus den Galaxien von Science-Fiction-Welten erinnere, müsse, so fordert 
Bailey, mit „deeper reflection [...] still bigger picture thinking and yet-grander imagination" begegnet werden (Bailey 2020a).

\section{"Make it gross"}

Am 21. April 2020 veröffentlichten zwei amerikanische Medizinrhetorikerinnen in einem Eintrag im Blog des Journals Medical Humanities einen provokativen Apell. Kristin Marie Bivens und Marie Moeller fordern: „Make COVID-19 Visuals Gross" (Bivens und Moeller 2020). In ihrem Artikel kritisieren Bivens und Moeller, die an unterschiedlichen amerikanischen Universitäten die Herausforderungen von Sprache und Kommunikation in der Medizin lehren und beforschen, das Bild des SARS-CoV-2 von Eckart und Higgins. Der ,Spiky Blob“ sei zwar „scientifically accurate and visually pleasing“, versäume aber gerade dadurch „the exigency of the current pandemic, the urgency of enacting certain behaviors during this global health crisis, and the human toll it is exacting across the globe" zu vermitteln. Durch die „scientifically-oriented representation“ des Virus werde so die Chance verfehlt, „behaviors and actions“ zu lenken. Da Covid-19 selbst, die Übertragungswege und der Einfluss, den die Krankheit auf die betroffenen Körper habe, „grotesque“, sogar „beyond humanizing visuals“ per se seien, fordern die Autorinnen "graphic and even grotesque imagery“ von Covid-19, kurz: „make it gross“. Doch das ist hochproblematisch. Denn es ruft ein Erbe der modernen Mikrobiologie auf (McLeod, Kershaw und Nerlich 2020), das seit einigen Jahren mit großem wissenschafts-rhetorischen Aufwand zu überwinden versucht wird (Institute of Medicine (U.S.) 2006) und sich in der bündigen Formel des Nobelpreisträgers Joshua Lederberg, „Teach war no more“, zusammenfassen lässt (Lederberg 2000, 245). Diesem Apell wird insbesondere angesichts eines antizipierten Endes der ,antibakteriellen Ära und eines möglicherweise damit einhergehenden Paradigmenwechsels in der Biomedizin prominent in der Mikrobiomforschung auf inter- und transdisziplinäre Weise in einer großen Zahl prestigeträchtiger Forschungsvorhaben Rechnung getragen, die die komplexen Beziehungen zwischen Menschen und Mikroben sowie ihrer Koexistenz mit Tieren und Pflanzen in ökologischen Konzepten neu zu perspektivieren versuchen (Morar und Bohannan 2019). 


\section{Das gefährliche Erbe der, goldenen Ära‘ der Bakteriologie}

Es ist die Vorstellung von potentiell pathogenen Mikroorganismen als unheimlichen Feinden, unsichtbaren Eindringlingen, die unmerklich die Körpergrenzen überwinden, die als Erbe der, goldenen Ära' der Bakteriologie bis heute besteht. Der Diskurs des im Laufe des 19. Jahrhunderts zur Sichtbarkeit gebrachten Mikrokosmos war schon von seinen Anfängen im 17. Jahrhundert an sowohl von Faszination als auch von Angst und Abwehr geprägt (Drews 2015, 1; Wilson 1995, 140; Nicolson 1976, 167-172). Die Idee gespenstisch-monströser Mikroben war dabei besonders wirkmächtig. Die Vorstellung von Monstern und Gespenstern als personifizierten „verstörenden Formen des Anderen" (Blanco und Peeren 2013, 3), die es vermögen, Grenze und Integrität des menschlichen Körpers zu verletzen, war bis weit in das 19. Jahrhundert tief im kollektiven Bewusstsein und im öffentlichen Diskurs verankert (Böhm und Sproll 2008, 37). Die sukzessive Enthüllung am Ende des 19. Jahrhunderts, dass Mikroben für tödliche Krankheiten wie Milzbrand, Tuberkulose oder Cholera verantwortlich sind, ist maßgeblich durch die mikrobiologischen Entdeckungen Louis Pasteurs (1822-1895) und die bakteriologischen Forschungen von Robert Koch vorangetrieben worden und knüpfte daher an eine schon seit Langem tradierte Vorstellung von Mikroben als unheimlichen Kreaturen, die unter anderem auch zu Krankheit und Tod führen können, an. Obwohl die Vorstellung gefährlicher Mikroben sowohl im zeitgenössischen populären Diskurs als auch in der visuellen und literarischen Imagination im 19. Jahrhundert vorherrschte, war sie unter den Wissenschaftlern der damaligen Zeit noch lange umstritten. Mit dem Nachweis ihres pathogenen Potenzials wurden die mikroskopischen Wesen, deren ontologische Zugehörigkeit bis dahin zwischen den Reichen der Flora und Fauna oszillierte, metaphorisch in bösartige Feinde transformiert, die den gesunden Körper durch Invasion bedrohten (Sarasin 2007, 454). Durch die Identifizierung der Mikrobe mit der Krankheit, die sie verursachen konnte, wurde ein kriegerischer mikrobieller Erreger konstruiert, der nun auch mit kriegerischen Mitteln bekämpft werden musste. Die ,goldene Ära' der Bakteriologie war seitdem deutlich gekennzeichnet durch Martialität sowohl in der Rede (populär und wissenschaftlich) als auch in konkreten Bekämpfungsmaßnahmen gegen die neu definierten „kleinsten, aber gefährlichsten Feinde der Menschheit" (Gradmann 2007, 330) sowie die Förderung eines neuen Hygieneregimes, den umfassenden Einsatz von Desinfektionsmitteln und später die Anwendung von Antibiotika. Eine dominante Metapher in den Beschreibungen der Beziehung zwischen Mensch 
und Mikroben war die des Krieges (Gradmann 2007, 334-337; Berger 2009, 186; Hänseler 2009, 109). Über Mikroben und den Umgang mit ihnen in dezidiert militärischen Begriffen zu sprechen war im späten 19. und frühen 20. Jahrhundert weit verbreitet und hat auch die Metaphorik des Mikrobiellen nachhaltig geprägt. Die fatale Eskalation dieser „kriegerischen Bildsprache“ ist ihre Implementierung in den rassistischen Antisemitismus des späten 19. Jahrhunderts mit dem gezielt diffamierenden Vergleich von Bakterien und Juden durch Paul de Lagarde (1827-1891). Zwar sollte sein Apell, „[m] it Trichinen und Bazillen wird nicht verhandelt, Trichinen und Bazillen werden auch nicht erzogen, sie werden so rasch und so gründlich wie möglich vernichtet“, vor allem zur „Enteignung, nicht zur Ermordung der Juden“ aufrufen (Gradmann 1996, 92), und doch, „wie Worte und Taten der Nationalsozialisten“ gezeigt haben, ist Lagardes Aufruf sehr wörtlich genommen worden (Gradmann 1996, 92).

\section{Der Krieg gegen den unsichtbaren Feind}

Auch zu Beginn der Corona-Pandemie wurde vielfach erneut das Bild des ,unsichtbaren Feindes ${ }^{6}$ heraufbeschworen, der aus der ,Fremde ${ }^{6}$ kommend seinen Siegeszug über den Globus angetreten hat und dem man den Krieg erklären müsse. ${ }^{2}$ Der französische Präsident Emmanuel Macron erklärte in seiner Rede an die Nation im März „Nous sommes en guerre“ und der US-amerikanische „Wartime“-Präsident Donald Trump verdeutlicht mit der Betitelung von SARS-CoV-2 als „China-Virus“ die xenophobische Dimension der militärischen Metaphorik im Kontext von Seuchen (Craig 2020, 3). Schon Susan Sontag hat in ihrem Aufsatz AIDS and its Metaphors eindrücklich vorgeführt, dass die beständige Reaktivierung der Kriegsmetaphorik im Angesicht von Seuchen hoch gefährlich ist:

The one I am most eager to see retired - more than ever since the emergence of AIDS - is the military metaphor. [...] [T] he effect of the military imagery on thinking about sickness and health is far from inconsequential. It overmobilizes, it overdescribes, and it powerfully contributes to the excommunicating and stigmatizing of the ill. No, it is not desirable for medicine, any more than for war, to be ,total'. [...] We

2 Auf den Seiten der Gesellschaft für deutsche Sprache e.V. (GfdS) findet sich eine ausführliche Linkliste mit Quellen zur Nutzung von Kriegsmetaphorik im Kontext von Covid-19 in der internationalen Politik (Gesellschaft für deutsche Sprache e.V. 2020). 
are not being invaded. The body is not a battlefield. The ill are neither unavoidable casualties nor the enemy. (Sontag 1989, 94-95)

Vor diesem Hintergrund ist es besonders wichtig, sich gegen eine durch möglichst viel Angst und Abscheu aufgeladene narrative wie visuelle Rhetorik der Virus-Darstellung auszusprechen. Die Sprachwissenschaftlerin Elisabeth Wehling verweist auf die ambivalente Macht von Kriegsmetaphorik: „Kriegerische Sprachbilder machen Angst, schüren das Bedürfnis nach Abschottung, mobilisieren aber auch eher zum Handeln." (Wehling 2020) Auch wenn Bivens und Moeller das letztgenannte disziplinarische Potential der Angst ins Feld führen, so ist dieses Kalkül heikel. Denn Angst ist und macht irrational. Die Kommunikationswissenschaftlerin Han Yu verweist daher auch zu Recht in einer Erwiderung auf die „Provocation“ von Bivens und Moeller darauf, dass viele Menschen durchaus Angst vor dem Virus hätten und die problematischen Konsequenzen, wie das Horten von Lebensmitteln und Hygieneartikeln oder die xenophobischen verbalen und körperlichen Angriffe asiatisch aussehenden Mitbürgerinnen und Mitbürgern gegenüber, dieser Angst deutlich zutage träten (Yu 2020). Sie gesteht, „, [g]iven this context, I fear the consequences of making COVID-19 visuals gross“ (Yu 2020). Robert Bailey vertritt in Anlehnung an Louis Althussers (1918-1990) Ideologie-Theorie die These, der ,Spiky Blob“ sei, von der staatlichen Gesundheitsbehörde in Auftrag gegeben, ein von den Medien als „ISA par excellence“ massenhaft distribuiertes, ideologisches Bild, „[that] tells us to be afraid for our lives and to act accordingly“. Dieses versetze die Öffentlichkeit somit permanent in einen Fluchtinstinkt, „that leads us to an isolating abyss of fear“ (Bailey 2020a). Und auch Han Yu legt in ihrer „Response“ dar, dass Versuche, insbesondere im Rahmen von Gesundheitskampagnen, Menschen durch Angst in eine bestimmte Verhaltensrichtung zu lenken, kontraproduktiv sein können, wenn ihnen keine effektiven Mittel zur Kontrolle des Risikos beigegeben werden, dem sie sich ausgesetzt fühlen sollen. Durch so genannte Furchtappelle bewusst erzeugte Angst könne Verleugnung, Vermeidung oder Widerstand hervorrufen. Da insbesondere in der visuellen Kommunikation diese negativen Auswirkungen verstärkt würden, weil die Wirkung von visuellen Darstellungen im Vergleich zu Texten unmittelbarer und tiefer gehend sei, hofft Yu auf eine Bildsprache des Virus, die „emphatic, sobering, and above all, informative“3 sei, während die Welt einen Weg durch die Pan-

3 Die Politikwissenschaftlerin Victoria Hattam hat kürzlich alternative wissenschaftliche Visualisierungen des Virus, die vom amerikanischen National Ins- 
demie zu finden versucht (Yu 2020). Diese Hoffnung verweist dezidiert auch auf eine mögliche Ethik der Ästhetik des wissenschaftlichen Bildes.

\section{Ethik der Ästhetik des wissenschaftlichen Bildes}

Der Auftrag, ein Portrait eines unbekannten Virus zu schaffen, um diesem eine Identität zu geben, ist eine besondere Herausforderung, denn ,in einem Bild [wird] die Sichtbarkeit von der Anwesenheit der Sache getrennt": „Ein Bild muß, um ein Bild zu sein, auf seiner Oberfläche etwas zeigen, das an dieser Stelle selbst nicht vorhanden ist. Jedes Bild ist ein sichtbarer Widerspruch von Präsenz und Absenz." Die Sichtbarkeit des Bildes selbst rückt damit in den Vordergrund (Wiesing 1997, 15). Insbesondere im Fall der Sichtbarmachung des Unsichtbaren, wie des SARS-CoV-2 gilt, laut dem amerikanischen Kommunikationswissenschaftler Derek Ross, der selbst viele Jahre als Wissenschaftsillustrator tätig war, ,[t]he images make the argument, in that they are critical to its presentation and ultimate reception" (Ross 2017, 167). Außerdem muss gefragt werden, was diese Bilder projizieren beziehungsweise, was auf sie projiziert wird, mit anderen Worten, „what will invested audiences themselves make of these images?" (Ross 2017, 168). Das wissenschaftliche Bild ist eine besondere Kunstform. Obgleich die Geschichte wissenschaftlicher Bilder weit zurückreicht und es spätestens seit Mitte des 20. Jahrhunderts, ausgehend von den frühen wissenschaftstheoretischen Überlegungen von beispielsweise Ludwig Fleck (Fleck 2014), vielfach eine theoretische Auseinandersetzung mit dem Phänomen wissenschaftlicher Bilder gab, fehlt eine „allgemeine Bildtheorie des wissenschaftlichen Bildes bisher" (Werner 2008, 30). Sowohl der Wissenschaft als auch der Kunst, als „regimes of knowledge, embedded in, but also constitutive of, the broader cultures they inhabit" (C.A. Jones und Galison 1998, 2) zuzuordnen, ist das wissenschaftliche Bild ein Hybrid. Es führt „[b]ezogen auf ein Wissen [...] verschiedene diskursive Praktiken zusammen" (Buchholz und Stahl 2014, 125) und muss „as evidence and art“ (Ross 2017, 151) zweierlei Dienst tun. Die ethische Dimension in dem Schaffensprozess wissenschaftlicher Bilder besteht für Ross in dem Vertrauensvorschuss in die Wissenschaft per se, für die das wissenschaftliche Bild symbolisch steht. Das Attri-

titute of Allergy and Infectious Diseases (NIAID) in Auftrag gegeben wurden, untersucht und die These aufgestellt: „that the NIAID images convey a "living with" rather than a "quarantining from" view of the COVID-19 (Hattam 2021, 13). 
but „scientific“ stehe für Glaubhaftigkeit und Legitimität (Ross 2017, 165). Insbesondere in Zeiten, in denen die Glaubwürdigkeit von Wissenschaft teilweise massiv in Frage gestellt wird, ist dieser Vertrauensvorschuss fragil, verleiht einer Ethik des wissenschaftlichen Bildes besonderen Nachdruck und fordert Wissenschaftsillustratorinnen und -illustratoren im besonderen Maße zur ethischen Reflexion ihrer Arbeit auf. Doch sind die Konsequenzen ihres künstlerischen Handelns nur bedingt kontrollierbar, wie das Bild des Virus paradigmatisch zeigt.

Die Produzentinnen und Produzenten wissenschaftlicher Bilder arbeiten hoch interdisziplinär. Während sie umfassende Kenntnisse des Wissenschaftsbereichs haben müssen, für den sie tätig sind, verstehen sie sich gleichzeitig als Künstler, die selbst wiederum den (wie auch immer unkonventionellen) Konventionen künstlerischen Schaffens verpflichtet sind. Sie müssen wissenschaftliche Akkuratesse mit einer genuinen Ästhetik verbinden, um eine eigene Bildsprache zu schaffen. Oftmals kommt ein dezidiert didaktischer Anspruch hinzu. Doch lassen sich die meist zu einem ganz bestimmten Zweck erzeugten Bilder nicht fest an diesen allein binden. Bilder, wie Texte, mögen einen Urheber oder eine Urheberin haben, mögen in einem bestimmten Kontext und in Hinblick auf ein bestimmtes Ziel entstanden sein. Doch weisen sie immer auch über diese Koordinaten hinaus. Sie dienen nicht nur der Vermittlung und Etablierung von Wissen, sondern sind integraler Bestandteil von Wissensproduktion selbst: „Bilder der Naturwissenschaften geben die Ergebnisse, die sie darzustellen haben, nicht passiv wieder, sondern sie prägen und erzeugen diese genuin aus ihrer eigenen Sphäre“ (Bredekamp, Schneider und Dünkel 2008, 8). Aufgrund des „Disjunktionsprinzip der naturwissenschaftlichen Darstellung“, das „das Paradoxon zu fassen [versucht], dass ein wissenschaftliches Bild oftmals umso stärker konstruiert ist, je natürlicher sein Gegenstand in der Widergabe erscheint", tendiere die Artifizialität, das Künstlerische des wissenschaftlichen Bildes, in Vergessenheit zu geraten (ebd., 9). Dies ist insofern problematisch, als dadurch eine Objektivität, ja sogar Realität eines Kunstproduktes angenommen wird, die dieses nie einlösen kann. (Wissenschaftliche) Bilder sind daher keine abgeschlossenen Produkte, sondern unterliegen einer Prozessualität, die ,in allen Komponenten ihrer Erzeugung nach ihren Techniken, Eingriffen, Kontexten und Akteuren" verstanden werden muss (ebd.).

Sie verfügen laut Horst Bredekamp über eine „Eigenaktivität“ (Bredekamp 2010, 53), haben eine Eigenlogik, entwickeln eine Eigendynamik und können damit zu einer spezifisch „ikonischen Erkenntnis“ führen (Buchholz 
und Stahl 2014, 127). Ihre „visuelle Evidenz“, die sich noch aus dem Ideal einer „mechanical objectivity“, wie sie das 19. Jahrhundert konstituierte (Daston und Galison 2010, 115ff.), herschreibt, ist jedoch hoch problematisch, wie auch der Fall des ,Spiky Blob“ eindrücklich zeigt. Denn auch er ist keine Abbildung der Realität, sondern dezidiert auf einen bestimmten Zweck hin konstruiert, nämlich, zunächst Aufmerksamkeit und dann sozial erwünschtes Verhalten, also Folgsamkeit, zu generieren. Eine Ethik des wissenschaftlichen Bildes fordert daher in erster Linie die Transparentmachung des Entstehungsprozesses, die Kenntnis über die historischen und symbolischen Bedeutungsebenen und die Bewusstmachung und Abwägung gewollter und ungewollter Konsequenzen des Rezeptionsprozesses.

\section{Kunst und Literatur in Krisenzeiten: „Because Survival is Insufficient"}

Es ist das immanent destabilisierende Moment von Seuchen, das diesen zugleich als Ursache und Marker von Krisen- und Umbruchsituationen innewohnt und das die Ordnungsprinzipien von Staat und Gesellschaft zu bedrohen vermag. Wie im Brennglas werden bereits vorhandene Probleme überdeutlich sichtbar, Latentes manifest. Eigenes Krankheitserleben, der Verlust von Angehörigen und Freunden, die Erfahrung der Isolation in den Phasen der mehr oder weniger massiven Einschränkungen des öffentlichen Lebens und der Alltagsroutinen und die Angst vor den wirtschaftlichen und sozialen Folgen der Pandemie können kollektiv wie individuell traumatisierend wirken. Insbesondere im Angesicht von Ausbrüchen bisher unbekannter Infektionskrankheiten (EID) verschärft das Nichtwissen die gefühlte und tatsächliche Bedrohungslage. Aus Unsicherheit entsteht Ohnmacht. Eine Phalanx interund transdisziplinär zusammenarbeitender Wissenschaften ist gezwungen, neue Wege zu betreten, um der existentiellen Bedrohung der Epidemie-Erfahrung zu begegnen. Es ist eine große gesellschaftliche Herausforderung, die Koexistenz etablierter und neu generierter, kon- und divergierender Wissensbestände einerseits zu vermitteln und andererseits auszuhalten. Dynamiken und Brüche der Wissensproduktion und -vermittlung werden unter anderem fachlich, politisch, gesellschaftlich und medial oft kontrovers diskutiert.

Kunst und Literatur fungieren als Seismographen und Inkubatoren gesellschaftlicher Prozesse und verweisen auf die existentielle Bedeutung von ästhetischem Schaffen als Reflexions- und Innovationsmedium per se und insbesondere in Krisenzeiten, wie sie die gegenwärtige Pandemie auf be- 
sondere Weise darstellt. Als elementare Komponenten ästhetischer, produktiver wie rezeptiver Erfahrung kommt ihnen in diesen komplexen Aushandlungsprozessen eine besondere Rolle zu. Als Reflexionsmedium spiegeln sie die vielgestaltigen Pandemie-Diskurse und bereichern diese insbesondere durch eine kritische Auseinandersetzung. Als Innovationsmedien vermitteln sie nicht nur Wissen, sondern generieren dieses selbst. Initiiert von einer kulturwissenschaftlich geöffneten Literaturwissenschaft wird inzwischen seit mehr als zwei Jahrzehnten nach den wechselseitigen Austauschprozessen von Wissen und Literatur im theoretischen Konzept einer „Poetologie des Wissens“ (Vogl 1999, 7) gefragt. Wiewohl für den Bereich der Kunst eine „allgemeine Epistemologie des Bildes“ (noch) fehlt, „gilt heute als unbestritten“, dass auch Bildern „eine wesentliche Rolle im Erkenntnisprozess zukommt“ (Buchholz und Stahl 2014, 126-127). Das innovative Potential von Kunst und Literatur, Wissen zu vermitteln, zu reflektieren und selbst hervorzubringen, ermöglicht durch einen „spielerisch-ästhetischen Umgang mit der Welt“ auch „menschliche Selbstüberschreitung“ (Wulf, Kamper und Gumbrecht 1994, IX). Indem die ästhetische Erfahrung „die Auseinandersetzung des Menschen mit seiner Lebenswelt zur Anschauung“ bringt, werden „Spielräume“ eröffnet, „die in vieler Hinsicht ethische Reflexionen und moralische Handlungsmöglichkeiten ermöglichen oder erweitern“ (Düwell 1999, 318). Wolfgang Welsch hat vielfach herausgestellt, dass Ethik und Ästhetik „durch essentielle Verflechtungen bestimmt sind“ (Welsch 1994, 4) und postuliert, dass die aisthesis in ihrer Doppelbedeutung von Wahrnehmen und Empfinden „zur Gänze vitalen Interessen, [...] dem Leben, dem Sich-am-Leben-Erhalten und Überleben“ (ebd., 6), diene und ästhetische Akte somit ein „Zumindest rudimentär ethische[s] Ziel“ verfolgten: die „Führung eines gelingenden Lebens“ (ebd.).

Somit ist es die Fähigkeit, ästhetischen Genuss zu empfinden und zu schaffen, die den Menschen, ist er auf seine Conditio humana zurückgeworfen, daran erinnert, was Menschsein bedeutet. Ein beeindruckendes Beispiel für die Signifikanz von Kunst in kunstfernen Zeiten ist der Roman Station Eleven der kanadischen Autorin Emily St. John Mandel aus dem Jahr 2014. In diesem für das Genre der Apocalyptic Fiction unkonventionellen Werk (Tate 2017, 132) imaginiert die Autorin eine postpandemische Zukunft und kontrastiert diese mit Momentaufnahmen der Zeit vor dem Ausbruch der "Georgia Flu“, „that exploded like a neutron bomb over the surface of the earth" (Mandel 2015, 36). Nachdem der Großteil der Zivilisation des frühen 21. Jahrhunderts innerhalb kürzester Zeit von einer neuartigen Grippe ver- 
heert wurde, bestehen zwanzig Jahre später nur noch vereinzelte zivilisatorische Inseln, die ohne die Errungenschaften der Vergangenheit, wie Elektrizität oder Medikamente, kaum mehr als existieren. Auch wenn der Roman die Anziehungskraft apokalyptischer Klischees durchaus anerkennt, vermeidet er die typische Formel „of death, destruction and regret in favour of a rather stranger, more resourceful, narrative" (Tate 2017, 133). Im Zentrum der Erzählung steht nicht der Kampf eines jeden gegen jeden ums nackte Überleben. Es ist vielmehr die Frage, was Menschsein im Ausnahmezustand ausmacht, denn, so die vielfach wiederholte Maxime des Narrativs, „[b]ecause survival is insufficient" (Mandel 2015, 58).

Die auktoriale Erzählinstanz stellt in dem programmatischen elften Kapitel des zweiten Teils heraus: „What was lost in the collapse: almost everything, almost everyone, but there is still such beauty" (ebd. 57). Für diese Schönheit, die sich nicht nur auf Kunstwerke im klassischen Sinn bezieht, steht das wenige ein, das von dem reichen kulturellen Erbe der präpandemischen Ära übrig geblieben ist: Einige Dramen Shakespeares und eine Handvoll klassischer Musikstücke, aufgeführt von der „Travelling Symphony“, einer Gruppe von Schauspielern und Musikern, die mit einem Planwagen durch die entvölkerte Grenzregion der Great Lakes zwischen Kanada und den USA streift. Das „Museum of Civilization“, das in einem alten Flugterminal angelegt wurde und in dem als Hort der immer mehr verblassenden Erinnerung an das „before“ (ebd., 20) Artefakte der vergangenen Zeit wie ein iPhone, eine Kreditkarte oder eine Schneekugel, ohne Nutzen, jedoch als „repository of beauty" (Vermeulen 2018, 18) von memorablem wie ästhetischem Wert, gesammelt und bewahrt werden. Die titelgebende Graphic Novel, $D r$. Eleven, die, entstanden in präpandemischen Zeiten, quasiprophetisch selbst von einer postapokalyptischen Welt handelt. Von individuell besonderer Bedeutung für nahezu alle Hauptfiguren ist sie strukturell wie symbolisch zentrales Verbindungselement aller Handlungs- und Zeitebenen. Verdichtet im lakonischen Ausspruch ihres Protagonisten, reflektiert das Buch im Buch als veritable mise en abyme das gegenwärtige Geschehen (Feldner 2018, 177): „I stood looking of my damaged home and tried to forget the sweetness of life on Earth" (Mandel 2015, 105, Kursivierung im Original). Daneben bilden Zeitungsauschnitte aus der Boulevardpresse, Interviews, Zitate aus Popsongs und Fernsehserien den auffallend selbstreferentiellen wie metapoetologischen, zum Teil ironisch gebrochenen, durchaus egalitär angelegten Kanon der kulturell-künstlerischen Relikte. So wird an einer Stelle darauf verwiesen, dass Shakespeares Stücke selbst in einer Zeit entstanden sind, 
in der „Plague closed the theatres again and again, death flickering over the landscape“ (ebd., 57), während an anderer Stelle der Refrain des R.E.M.-Liedes „It's the end of the world as we know it“ als perfekter Soundtrack zum Weltuntergang einen der Protagonisten heimsucht (ebd., 176). Und selbst der hochphilosophisch anmutende Leitsatz des Romans, „[b]ecause survival is insuffient“, der weiß leuchtend als Schriftzug den Karavan der „Travelling Symphony“ und als tiefschwarz in die Haut tätowierte Mahnung den Unterarm einer der Schauspielerinnen ziert, stammt nicht etwa von einem der großen Denker der vorpandemischen Ära, sondern wurde einer Folge der Serie Star Trek: Voyager entliehen (ebd., 119). Die Romanhandlung rangiert auf drei zeitlichen Ebenen, die auf komplexe Weise eng miteinander verwoben sind. Dabei liegt der erzählerische Fokus auf einer Reihe unterschiedlicher Protagonisten und Protagonistinnen, deren Lebensläufe sich ebenfalls kreuzen. Auf allen drei Zeitebenen und für alle Handlungstragenden ist Kunst in den unterschiedlichsten Ausformungen von existentieller Bedeutung. Das dichte Netz intertextueller und intermedialer Bezüge bildet die Matrix des Romangeschehens, verbindet Vergangenheit, Gegenwart und Zukunft, Hoch- und Populärkultur. Diese selbst kunstvoll gearbeiteten Querverstrebungen bilden gewissermaßen den doppelten Boden der zivilisatorischen Identität der Romanwelt und verweisen beständig auf das Diktum der Erzählung, dass es nicht nur ums Überleben allein gehen kann, sondern dass „humanity redeems itself through culture“ (Feldner 2018, 175).

Die Kraft ästhetischen Produzierens und Rezipierens erhebt Kunst und Literatur über den Status eines reinen Speichermediums historischer Begebenheiten oder über ihr unterhaltendes, gar eskapistisches Potential hinaus und plädiert für ein l'art pour l'art, „obgleich und weil sich als dessen tiefere Deutung la vie pour l'art und l'art pour la vie offenbart“ (Simmel 2000, 15). Insbesondere in Zeiten der Unsicherheit und (existentiellen) Bedrohung leisten Kunst und Literatur durch ihren „Widerstand gegen Versuche, das Geheimnis [...] des Anderen abzuschaffen, und ihr Eintreten für das Unsagbare und das Undurchschaubare“, einen „Beitrag zur Offenheit für das Fremde und zur Sorge für das Andere und damit zu einer Ethik menschlicher Existenz" (Wulf, Kamper und Gumbrecht 1994, XI). In der kritischen Auseinandersetzung mit den visuellen und narrativen Traditionen und den historischen Kontexten epidemischer Kunst- und Literaturproduktion können Kunst und Literatur kreativ auf die Bedrohungen der Gegenwart reagieren und aktiv eine (post)pandemische Zukunft mitgestalten. Sie entfalten eine eigene Handlungsmacht, die angesichts der Grenzen des Wissens in pan- 
demischen Zeiten der Komplexität und den Widersprüchlichkeiten akuter Unsicherheitserfahrung nachforscht und sich diese im Prozess ästhetischen Schaffens zu eigen macht. Die Vielfalt der künstlerischen Aneignung, die die Embleme der gegenwärtigen Pandemie, die Maske und das Bild des Virus, bis jetzt hervorgebracht haben, zeigt, wie alternative Visualisierungsund Narrativierungsstrategien Angst abbauen, Hoffnung schaffen und zur Deeskalation einer von Feindbildern und Bedrohungsszenarien geprägten Pandemie-Rhetorik beitragen können.

\section{Literatur}

Bachtin, Michail. 1995. Rabelais und seine Welt. Volkskultur als Gegenkultur. Herausgegeben von Renate Lachmann. Übersetzt von Gabriele Leupold. Suhrkamp-Taschenbuch Wissenschaft 1187. Frankfurt am Main: Suhrkamp Verlag.

Bailey, Robert. 2020a. „The Coronavirus Looks Like Neoliberalism, Part One: The ,Spiky Blob““. Inhabiting the Anthropocene (blog). 3. Juni 2020. https://inhabitingtheanthropocene.com/2020/06/o3/the-coronavirus-looks-like-neoliberalism-part-one-the-spiky-blob/.

- - . 2020b. „The Coronavirus Looks Like Neoliberalism, Part Two: Images and Counterimages“. Inhabiting the Anthropocene (blog). 10. Juni 2020. https://inhabitingtheanthropocene.com/2020/o6/10/the-coronavirus-looks-like-neoliberalism-part-two-images-and-counterimages/.

Belting, Hans. 2013. Faces: eine Geschichte des Gesichts. München: C.H. Beck.

Berger, Silvia. 2009. Bakterien in Krieg und Frieden: eine Geschichte der medizinischen Bakteriologie in Deutschland 1890-1933. Göttingen: Wallstein.

Bivens, Kristin Marie, und Marie Moeller. 2020. „Make COVID-19 Visuals Gross““. Blog Medical Humanities (blog). 21. April 2020. https://blogs.bmj.com/ medical-humanities/2020/04/21/make-covid-19-visuals-gross/?fbclid=IwAR2V7kQpy56F53DiauqCoChkztf3-yXikruSocM-3Hq69oOZo5tk8gh2tF8\&int_source=trendmd\&int_medium $=$ cpc\&int_campaign=usage-042019.

Blanco, María del Pilar, und Esther Peeren, Hrsg. 2013. „Introduction: Conceptutalizing spectralities“. In The spectralities reader: ghosts and haunting in contemporary cultural theory, 1-28. New York: Bloomsbury Academic.

Boccaccio, Giovanni. 2011. Il Decameron: novelle scelte; mit Holzschnitten der Ausgabe von 1492. Herausgegeben von Kerstin Marfordt. Reclams Universal-Bibliothek Fremdsprachentexte Italienisch 19792. Stuttgart: Reclam.

Boeckl, Christine M. 2000. Images of plague and pestilence: iconography and iconology. Sixteenth century essays \& studies 53. Kirksville, MO: Truman State University Press. 
Böhm, Alexandra, und Monika Sproll. 2008. „Ein ,Schlag ans Herz des Empire William Heaths Karikatur ,Monster Soup““. In Fremde Figuren. Alterisierungen in Kunst, Wissenschaft und Anthropologie um 180o, herausgegeben von Alexandra Böhm und Monika Sproll, 27-40. Würzburg: Königshausen \& Neumann.

Bredekamp, Horst. 2010. Theorie des Bildakts. 1. Aufl. Frankfurt: Suhrkamp.

Bredekamp, Horst, Birgit Schneider und Vera Dünkel. 2008. „Editorial: Das Technische Bild“. In Das Technische Bild: Kompendium zu einer Stilgeschichte wissenschaftlicher Bilder, herausgegeben von Horst Bredekamp, Birgit Schneider und Vera Dünkel. Berlin: Akademie Verlag.

Briese, Olaf. 2003. Angst in den Zeiten der Cholera. Über kulturelle Ursprünge des Bakteriums: Seuchen-Cordon I. Bd. 1. Angst in den Zeiten der Cholera. Berlin: De Gruyter.

Bruner, Raisa. 2020. „How People Imitating Masterful Paintings Launched a Sweeping Trend From Italy to Iceland“. Time. 10. April 2020. https://time.com/5817117/ coronavirus-art-history/.

Buchholz, Amrei, und Lina Maria Stahl. 2014. „Epistemologie: Bilder des Wissens“. In Bild: ein interdisziplinäres Handbuch, herausgegeben von Stephan Günzel, Dieter Mersch und Franziska Kümmerling, 125-130. Stuttgart: Metzler.

Bundesministerium für Gesundheit. 2020. „Einfach erklärt: Ein neuer Alltag“. Zusammen gegen Corona. 25. Mai 2020. https://www.zusammengegencorona.de/ informieren/ein-neuer-alltag/.

Camus, Albert. 2015. La peste. Nachdr. Collection Folio 42. Paris: Gallimard.

Craig, David. 2020. „Pandemic and Its Metaphors: Sontag Revisited in the COVID-19 Era“. European Journal of Cultural Studies, 23 (Juli), 1025-1032. https://doi. org/10.1177/1367549420938403.

Daston, Lorraine, und Peter Galison. 2010. Objectivity. Paperback ed. New York, NY: Zone Books.

Defoe, Daniel. 2010. A Journal of the Plague Year. Herausgegeben von Louis A. Landa. Überarb. Aufl. Oxford World's Classics. New York: Oxford University Press.

Dorn, Thea. 2021. Trost: Briefe an Max. München: Penguin Verlag.

Drews, Gerhart. 2015. Bakterien - ihre Entdeckung und Bedeutung für Natur und Mensch. 2., überarb. und aktualisierte Aufl. Berlin: Springer Spektrum.

Dusl, Andrea Maria. 2020. In Zeiten des Coronavirus: Die Angst vor der Maske, 1. März 2020. https://www.derstandard.at/story/2000115128778/die-angst-vorder-maske.

Düwell, Marcus. 1999. Ästhetische Erfahrung und Moral: zur Bedeutung des Ästhetischen für die Handlungsspielräume des Menschen. Alber-Reihe Thesen, Bd. 4. Freiburg: Verlag K. Alber.

Emcke, Carolin. 2020. „Journal - politisch-persönliche Notizen zur Corona-Krise“. Süddeutsche Zeitung Projekte. 2020. https://projekte.sueddeutsche.de/artikel/ politik/corona-krise-journal-in-zeiten-der-pandemie-e882426/. 
Feldner, Maximilian. 2018. „Survival Is Insufficient': The Postapocalyptic Imagination of Emily St. John Mandel's Station Eleven“. Anglica. An International Journal of English Studies, no. 27/1: 165-179. https://doi.org/10.7311/08605734.27.1.12.

Flaskerud, Jacquelyn H. 2020. „Masks, Politics, Culture and Health“. Issues in Mental Health Nursing, Juli, 1-4. https://doi.org/10.1080/01612840.2020.1779883.

Fleck, Ludwig. 2014. „Schauen, Sehen, Wissen“. In Bildwissenschaft und Visual Culture, herausgegeben von Marius Rimmele, Klaus Sachs-Hombach und Bernd Stiegler, 295-315. Basis-Script 4. Bielefeld: Transcript.

Friedmann, Vanessa. 2020. „The Mask: The surgical face mask has become a symbol of our times“. New York Times, 17. März 2020. https://www.nytimes. com/2020/03/17/style/face-mask-coronavirus.html.

Gesellschaft für deutsche Sprache e.V. (GfdS). 2020. Virus-Kampf, Notabitur und neue Helden: Kriegsmetaphern und Krisen-Begriffe im Diskurs um die Covid-19-Pandemie. Blog. https://gfds.de/kriegsmetaphern-und-krisen-begriffe/.

Giaimo, Cara. 2020. „The Spiky Blob Seen Around the World: How C.D.C medical illustrators created the coronavirus pandemic's most iconic image". New York Times, 1. April 2020. https://www.nytimes.com/2020/04/o1/health/coronavirus-illustration-cdc.html.

Goh, Yihui, Benjamin Y.Q. Tan, Chandra Bhartendu, Jonathan J.Y. Ong und Vijay K. Sharma. 2020. „The Face Mask: How a Real Protection Becomes a Psychological Symbol during Covid-19?“. Brain, Behavior, and Immunity 88 (August): 1-5. https://doi.org/10.1016/j.bbi.2020.05.060.

Gradmann, Christoph. 1996. „Bazillen, Krankheit und Krieg. Bakteriologie und politische Sprache im deutschen Kaiserreich“. Berichte zur Wissenschaftsgeschichte 19 (2-3): 81-94. https://doi.org/10.1002/bewi.19960190204.

---. 2007. „Unsichtbare Feinde. Bakteriologie und politische Sprache im deutschen Kaiserreich“. In Bakteriologie und Moderne. Studien zur Biopolitik des Unsichtbaren 1870-1920. Hrsg. von Philipp Sarasin, Silvia Berger, Marianne Hänseler und Myriam Spörri, 327-374. Suhrkamp Taschenbuch Wissenschaft 1807. Frankfurt am Main: Suhrkamp.

Grünbein, Durs. 2020. „Ein Feind, unsichtbar“. Süddeutsche Zeitung, Feuilleton, 8. April 2020.

Hänseler, Marianne. 2009. Metaphern unter dem Mikroskop: die epistemische Rolle von Metaphorik in den Wissenschaften und in Robert Kochs Bakteriologie. Legierungen 6. Zürich: Chronos.

Hattam, Victoria (2021) Visualizing the Virus, Design and Culture, 13:1, 9-17, DOI: 10.1080/17547075.2020.1869454

Heine, Heinrich. 1980. „Französische Zustände“. In Historisch-kritische Gesamtausgabe der Werke. 12,1: Französische Maler, Französische Zustände [u.a.], herausgegeben von Jean-René Derré und Manfred Windfuhr, 1. Aufl. Hamburg: Hoffmann u. Campe. 
Hindhal, Philipp. 2020. „The New Normal: A Cultural History of Masks“. Schirn Mag. 7. Mai 2020. https://www.schirn.de/en/magazine/antsy/2020/the_new_ normal_a_cultural_history_of_masks/.

Hüls, Ansgar Michael. 2013. Maske und Identität: das Maskenmotiv in Literatur, Philosophie und Kunst um 190o. Epistemata. Reihe Literaturwissenschaft, Bd. 784. Würzburg: Königshausen \& Neumann.

Institute of Medicine (U.S.), Hrsg. 2006. Ending the war metaphor: the changing agenda for unraveling the host-microbe relationship: workshop summary. Washington, DC: National Academies Press.

Jones, Caroline A., und Peter Galison. 1998. „Picturing Science, producing art“. In Picturing science, producing art, herausgegeben von Caroline A. Jones, Peter Galison und Amy E. Slaton. New York: Routledge.

Jones, Kate E., Nikkita G. Patel, Marc A. Levy, Adam Storeygard, Deborah Balk, John L. Gittleman und Peter Daszak. 2008. „Global Trends in Emerging Infectious Diseases“. Nature 451 (7181): 990-993. https://doi.org/10.1038/natureo6536.

Lederberg, J. 2000. „Infectious History“. Science 288 (5464): 287-293. https://doi. org/10.1126/science.288.5464.287.

Link, Franz H. 1993. „Tanz und Tod in Kunst und Literatur: Beispiele“. In Tanz und Tod in Kunst und Literatur, herausgegeben von Franz H. Link, 11-68. Schriften zur Literaturwissenschaft, Bd. 8. Berlin: Duncker \& Humblot.

Link, Jürgen. 1988. „Literaturanalyse als Interdiskursanalyse“. In Diskurstheorien und Literaturwissenschaft, herausgegeben von Jürgen Fohrmann und Harro Müller, 1. Aufl., 284-310. Suhrkamp Taschenbuch Materialien 2091. Frankfurt am Main: Suhrkamp.

Lynteris, Christos. 2018. „Plague Masks: The Visual Emergence of Anti-Epidemic Personal Protection Equipment“. Medical Anthropology 37(6): 442-457. https:// doi.org/10.1080/01459740.2017.1423072.

Mandel, Emily St John. 2015. Station Eleven. London: Picador.

Manzoni, Alessandro. 2014. I promessi sposi: storia milanese del secolo XVII. Herausgegeben von Kerstin Marfordt. Ed. ridotta. Reclams Universal-Bibliothek Fremdsprachentexte Italienisch 19861. Stuttgart: Reclam.

Marchal, Kai. 2020. „Atemschutzmasken: Im Angesicht des Virus“. Zeit Online, 2. April 2020. https://www.zeit.de/kultur/2020-04/atemschutzmasken-coronavirus-asien-europa-unterschiede.

Matuschek, Christiane, Friedrich Moll, Heiner Fangerau, Johannes C. Fischer, Kurt Zänker, Martijn van Griensven, Marion Schneider u. a. 2020. „The History and Value of Face Masks“. European Journal of Medical Research 25(1): 23. https:// doi.org/10.1186/s40001-020-00423-4.

McLeod, Carmen, Eleanor Hadley Kershaw, und Brigitte Nerlich. 2020. „Fearful Intimacies: COVID-19 and the Reshaping of Human-Microbial Relations". Anthropology in Action 27 (2): 33-39. https://doi.org/10.3167/aia.2020.270205. 
Morar, Nicolae, und Brendan J. M. Bohannan. 2019. „The Conceptual Ecology of the Human Microbiome“. The Quarterly Review of Biology 94(2): 149-175. https:// doi.org/10.1086/703582.

Nicolson, Marjorie Hope. 1976. Science and imagination. Hamden, Conn: Archon Books.

Poe, Edgar Allan. 1978. „The Masque of the Red Death“. In The Collected Works of Edgar Allan Poe, herausgegeben von Thomas Ollive Mabbott, Bd. II: Tales and Sketches, 1831-1842: 667-678. Cambridge, Massachusetts, London, England: Belknap Press of Harvard University Press.

Ross, Derek G. 2017. „The Role of Ethics, Culture, and Artistry in Scientific Illustration“. Technical Communication Quarterly 26(2): 145-172. https://doi.org/10.1 080/10572252.2017.1287376.

Ruisinger, Marion Maria. 2020. „Die Pestarztmaske im Deutschen Medizinhistorischen Museum Ingolstadt“. NTM Zeitschrift für Geschichte der Wissenschaften, Technik und Medizin 28(2): 235-252. https://doi.org/10.1007/s00048-02000255-7.

Sarasin, Philipp. 2007. „Die Visualisierung des Feindes. Über metaphorische Technologien der frühen Bakteriologie“. In Bakteriologie und Moderne. Studien zur Biopolilitk des Unsichtbaren 1870-1920, 427-461. Suhrkamp Taschenbuch Wissenschaft 1807. Frankfurt am Main: Suhrkamp.

Schonlau, Anja. 2009. „Warum trägt der Tod eine Maske? Zu Kultur- und Literaturgeschichte allegorischer Seuchendarstellung am Beispiel von Gerhart Hauptmanns Pestdrama ,Die Maske““. In Narren, Masken, Karneval: Meisterwerke von Dürer bis Kubin aus der Düsseldorfer Graphiksammlung „Mensch und Tod“, herausgegeben von Stefanie A. Knöll und Heinrich-Heine-Universität Düsseldorf, 1. Aufl, 62-71. Regensburg: Schnell \& Steiner.

Schulte, Brigitte. 2007. „Totentanz“. In Reallexikon der deutschen Literaturwissenschaft: Neubearbeitung des Reallexikons der deutschen Literaturgeschichte, herausgegeben von Klaus Weimar, Harald Fricke und Jan-Dirk Müller, 657-660. Berlin: de Gruyter.

Simmel, Georg. 2000. „L'art pour l'art“. In Aufsätze und Abhandlungen, 1909-1918, herausgegeben von Klaus Latzel und Otthein Rammstedt, 1. Aufl, 9-15. Gesamtausgabe/Georg Simmel, Bd. 13. Frankfurt am Main: Suhrkamp.

Snow, C.P. 1993. The two cultures. Canto ed. London, New York: Cambridge University Press.

Sontag, Susan. 1989. AIDS and its metaphors. 1. Aufl., New York: Farrar, Straus and Giroux.

Strasser, Bruno J., und Thomas Schlich. 2020. „A History of the Medical Mask and the Rise of Throwaway Culture“. The Lancet 396 (10243): 19-20. https://doi. org/10.1016/So140-6736(20)31207-1.

Tate, Andrew. 2017. Apocalyptic Fiction. 21st Century Genre Fiction. London, New York: Bloomsbury Academic. 
Vermeulen, Pieter. 2018. „Beauty That Must Die: Station Eleven, Climate Change Fiction, and the Life of Form“. Studies in the Novel 50, no. 1: 9-25. https://doi. org/10.1353/sdn.2018.0001.

Vogl, Joseph. 1999. „Einleitung“. In Poetologien des Wissens um 18oo, herausgegeben von Joseph Vogl, 7-16. München: Fink.

Wald, Priscilla. 2008. Contagious: cultures, carriers, and the outbreak narrative. Durham: Duke University Press.

Wehling, Elisabeth. 2020. Elisabeth Wehling: Die Macht der Worte in der Corona-Krise. Interviewt von Anja Reschke. Podcast. https://www.ndr.de/kultur/After-Corona-Club-mit-Elisabeth-Wehling,wehling112.html.

Weihe, Richard. 2004. Die Paradoxie der Maske: Geschichte einer Form. München: Wilhelm Fink.

Welsch, Wolfgang. 1994. „Ästhe/thik“. In Ethik der Ästhetik, herausgegeben von Christoph Wulf, Dietmar Kamper und Hans Ulrich Gumbrecht, 3-22. Acta humaniora. Berlin: Akademie Verlag.

Werner, Gabriele. 2008. „Bilddiskurse“. In Das Technische Bild: Kompendium zu einer Stilgeschichte wissenschaftlicher Bilder, herausgegeben von Horst Bredekamp, Birgit Schneider und Vera Dünkel, 30-35. Berlin: Akademie Verlag.

Wiesing, Lambert. 1997. Die Sichtbarkeit des Bildes: Geschichte und Perspektiven der formalen Ästhetik. 1. Aufl. rowohlts enzyklopädie 579. Reinbek b. Hamburg: Rowohlt.

Wilson, Catherine. 1995. The invisible world: early modern philosophy and the invention of the microscope. Studies in intellectual history and the history of philosophy. Princeton, N.J: Princeton University Press.

Wulf, Christoph, Dietmar Kamper und Hans Ulrich Gumbrecht. 1994. „Einleitung“. In Ethik der Ästhetik, herausgegeben von Christoph Wulf, Dietmar Kamper und Hans Ulrich Gumbrecht. Acta humaniora. Berlin: Akademie Verlag.

Yu, Han. 2020. „Responseto,Make COVID-19Visuals Gross““. Blog Medical Humanities (blog). 28. Mai 2020. https://blogs.bmj.com/medical-humanities/2020/05/28/ response-to-make-covid-19-visuals-gross/?utm_campaign=shareaholic\&utm_ medium =facebook\&utm_source=socialnetwork\&int_source=trendmd\&int_medium=cpc\&int_campaign=usage-042019. 
